\title{
IT and tourism: still a hot topic, but do not forget IT
}

\author{
Julia Neidhardt ${ }^{1}$ iD $\cdot$ Hannes Werthner ${ }^{1}$
}

Received: 24 June 2018 / Accepted: 3 August 2018 / Published online: 10 August 2018

(c) The Author(s) 2018

\begin{abstract}
More and more aspects of our life "move" to the Web. The Web and the Internet, as the underlying information infrastructure and "machine", can be considered as a mirror of the "real" physical world. However, the Web is not only reflecting this world, it is obviously also transforming it, where it is increasingly hard to distinguish between the physical and the virtual. It acts both as an enabler and driver of new, technical, economic and societal developments. With recent achievements in areas such as machine learning, Internet of Things or artificial intelligence (or rather intelligent assistance-a probably more appropriate term), we see the power of computer science. In this short comment, we argue that IT and tourism is still a hot topic, also or especially from a scientific point of view. However, from this latter point of view this might change, and we claim that, in order to prevent the field from becoming insignificant, more emphasis must be put on technical and formal aspects of science. We do not know the future, we are not "futurologists" (In a marketing note of an innovation and technology conference, the organizers even wanted to provide a look beyond the future-we have no idea how this nonsense could be done!), but we take the freedom to highlight some issues, which we consider to be important-in particular since one of the authors has a background of driving the field for nearly 30 years.
\end{abstract}

Keywords e-Tourism $\cdot$ Information technology $\cdot$ Computer science $\cdot$ IT-based innovation - Tourism research

\section{1 e-Tourism and a short history (without numbers)}

In accordance with Werthner and Klein (1999), we base our discussion on the following definition of e-tourism: e-tourism denotes the analysis, design, implementation and application of IT/e-commerce solutions in the travel and tourism

Julia Neidhardt

julia.neidhardt@ec.tuwien.ac.at

http://www.ec.tuwien.ac.at/neidhardt

1 Faculty of Informatics, TU Wien, Favoritenstrasse 9-11/194-04, 1040 Vienna, Austria 
industry, as well as the analysis (of the impact) of the respective technical/economic processes and market structures. This non-normative definition contains a constructive and an analytical part, needing a mixture of methods coming from engineering, mathematics and science.

One of the authors was almost thrown out of the room when telling the industry that IT would become THE factor of their business in 1994. But, IT has radically changed the industry; one might also say, IT created a new industry. Today, we have a well-developed business landscape in tourism, where we moved from simple Websites to partnerships and to IT-based business networks, leading to a so-called "informatization" of the entire value chain. In addition, since e-commerce favors, in tendency, consumers, we moved from a "customer focused" to a "customer driven" industry, which becomes obvious when looking at online communities or social media sites and their respective power. Moreover, online services became commodities, with an ongoing deconstruction of the value chain. This means, that nowadays you do not need to develop yourselves all your IT services; you just use pre-existing ones on the Web, which provide standard interfaces. In this complex mix of partnering and evolving IT structure, the emphasis moved (or should have moved) from process re-engineering, to network engineering, which implies that in complex network structures of companies and services, enterprises have to focus more on their value contribution (asking, what is their respective added value) and not so much on efficiency. This might be a little bit provocative, but otherwise they run into the risk to produce very efficiently things, which nobody needs. At the same time, we see an enormous trend towards concentration, where the winner takes it all. In some sense, the development of the Web can be seen as an evolution that lead to both order (i.e. highly centralized) and disorder (i.e. permanent appearance of new services and technologies).

A second general phenomenon worth mentioning might be characterized as a transparency paradox: more and more information leads to increasing and decreasing transparency at the same time. On the one hand, all this information is available and can be accessed. On the other hand, the amount of available information is likely to lead to information overload, where it might be hard for the users to find what they are actually looking for. Search tools and recommender systems are available and can help to address this problem, but users typically do not know how these systems exactly work and what data they exploit. All of this is increasingly leading to a feeling of insecurity and related problems of trust.

Finally, IT-based newcomers were driving innovation with their fast imitation of business models and technology, whereas traditional market players had problems with service innovation, business models and technology development. These newcomers became very fast the new and now stronger middlemen (compared to pre-Web times). In the two-sided market, where suppliers sponsored consumers (consumers pay with their data), the network effect favored this development. Fragmented supplier markets, constituted mainly by SMEs, could not compete with the new players. In addition, these new companies primarily focused on the market (transaction) and not on the product itself. They conquered the consumers very fast, providing the necessary information and trust functions in an information asymmetric market. The initial hope of the start time of the 
1990s of direct distribution and a direct link from suppliers to consumers was not fulfilled (or even worsened?).

This reads like a history of e-commerce, but it is one of e-tourism. The reason is that e-tourism was at the forefront of the general development (and still is) due to its inherent features (Werthner and Ricci 2004).

\section{Current situation and dominance of platforms}

The travel and tourism industry is still a major application area for IT, with many technical innovations including recommender systems, emotional computing, group decisions, social media and analytics. However, currently the most important aspect is probably the dominance of IT-based platform businesses. For example, this is also true for the sharing economy, which has been emerging very fast. It has to be pointed out that, with respect to the sharing economy, first and major examples can be located in tourism and mobility as well, namely, Airbnb and Uber. This underlines the up-to-date importance of this industry sector.

IT-based innovations, also in the tourism market, are often connected with socalled platform strategies. Such platforms offer technologies and services for a broad ecosystem of users and companies (Cusumano 2010a). External innovations create these ecosystems around the platform (Cusumano 2008). Functionalities are provided by partners or competitors, which also use these services at the same time. The platform operator provides the basic functionality and opens the platform to enable external innovation. This presents a competitive advantage over so-called pure product solutions that have to constantly implement and integrate their own services and innovations. Platforms have to meet two conditions: first, there must be at least one open technical interface as "a system of use" and second, it has to be easy to get and stay connected. Switching costs and bundling form a strategically important part of platforms by attracting users to their platforms and by offering many different features for one low price and retain users by making it technically difficult to move to another platform (Cusumano 2010b). Obviously, the value of a platform increases with the number of participating companies and/or users.

Tourism, illustrated by the history of e-tourism, is an excellent example for such innovation approaches. Take Online Travel Agencies (OTA), for example: they will continue to grow, with a monopolistic tendency. Due to positive network effects in the two-sided market, the already strong platforms will become stronger with every additional input (e.g., hotels, customers, reviews, etc.). The more hotels rely on the different platforms and distribute their rooms through them, the greater the market power of the latter. Owing to the competition and the importance of the OTAs, providers are forced onto such platforms. Comparison-based on only a few parameters-eases the cognitive load of customers, with the negative consequence of lowered prices for the service providers. Similar considerations are valid for search engines or social media sites. The activities on these sites increase the expenses of the service providers and strengthen the network effects of the platforms. This creates a paradoxical spiral: the expenditures of the service provider increase to the same extent as their dependence on the latter, including higher costs. The spiral is 
like a vicious circle: The more effort is made by suppliers, the weaker becomes their position with regard to these "central" organizations.

It is an ironic fact that tourist destinations would nearly perfectly meet the prerequisites for an industry service platform. They already have the required regional/ national ecosystem (i.e., users, service providers, complementary services and products, content, advertisers and channel partners) to form a successful platform. There is a kind of a structural equivalence of a Web network/platform strategy and a destination's cooperation strategy. This is also valid for the cooperation with other industries which is especially important, since tourists look for a bundle of comprehensive tourism experiences, not only for hotels or individual activities. Finally, such a platform would enable the bundling of know-how, and the gathering of data for the analysis of consumer behavioral or product development. And it would ease the participation in a wider innovation process. However, this opportunity has not been taken by the destinations (Calatrava Moreno et al. 2015).

\section{3 e-Tourism as a scientific field}

With respect to research topics in e-tourism, several reviews of scientific contributions of the previous 10-20 years were published, such as (Buhalis and Law 2008) or (Wang et al. 2010), with similar results. From a historical perspective, three main general topics were identified including: (1) consumers and demand dimension including changes of travel behavior due to the Web, information search as relevant part of the purchase decision, the emergence of Web 2.0 bringing together online social networks and tourism, choice overload and recommender systems/personalization as countermeasure; (2) more IT and technological issues including interoperability, ontologies and Semantic Web, multimedia and virtual reality, mobile and wireless technologies, Web design and accessibility and ambient intelligence (now called IoT); and (3) industry and business functions including strategic and operational dimensions, competitiveness, marketing and distribution and adoption. Particularly in the early days, research rather focused on technical issues and on showing how to automate processes through IT. However, this has been gradually changing, and social sciences and marketing aspects have been gaining more and more importance in e-tourism journals. Similarly, with respect to the methodological approach, the field moved away from engineering and system design with its constructive approach to empirical studies, case studies and, recently, data driven approaches. (In this context, it is interesting that one of the authors of this commentary gave a keynote on data science, network science and service science already at ENTER 2006.)

In recent years, the number of quantitative papers is rising, as is their quality. The availability of data and tools, which has an impact on the way social sciences work in general (Lazer et al. 2009), might be a reason. However, it is worth pointing out that research in the e-tourism field still mainly relies on data acquired by questionnaires and surveys rather than open data or large-scale Web-based data, as a survey of used data sources of all publications in the ENTER 2017 proceedings suggests (Sertkan 2018). 
A critical issue is that rather few articles on tourism applications can be found in pure computer science journals. In those articles that exist and where tourism serves as an application domain, the specific features of the field, which are particularly challenging, or the potential of the domain are typically not mentioned. Another observation indicates that with respect to strategies, the field moves from the macro level to the micro level, i.e., the focus is on adoption and/or marketing for individual enterprises, which involves the danger of losing the big picture at the macro and strategic industry scale. However, this point of view would be required to cover the aspects of platform strategies, power relationships or structural changes in a complex market, the latter having been a hot topic in the early days of e-tourism.

Finally, the e-tourism topic is spreading to (nearly) all tourism and hospitality research journals, with a clear focus on organizational, business, or marketing issues, losing the close relation to computer science. Or put differently, it is about observing adoption, and not on designing and implementing new solutions. A similar pattern can be observed at the conference side, where more and more industry e-tourism conferences are organized, with little scientific base at all-where tourism researchers - to put in a provocative way - take the loud marketing claims of IT and e-commerce companies as granted. With respect to both phenomena, the spread to tourism journals as well as the rise of industry driven e-tourism conferences, a strong scientific e-tourism base would be needed.

\section{Invariants and important issues for the future}

We like to remember that the tourism product as well as the tourism industry have special, inherent features, which emphasize the important relationship between IT and tourism (Werthner and Klein 1999). As a consequence, travel and tourism can be regarded as a critical test and application field for computer science, which, in turn, is enabling new services, products and co-operations for the tourism domain.

The special features of the tourism product include that it is an experience good, thus information based, and that it is - normally - an aggregated product, consisting of legally, economically and geographically distributed parts. Thus, integration of different players — with different business rules and objectives — on the fly is required. Consequently, the (virtual or physical) intermediary or product aggregator/ assembler (who might also be the user) has a specific role. A rather tricky issue is that the tourism product is defined by the tourist. Nearly every product can become a tourism product, when it is consumed by the tourist. Thus, from a computer science point of view, domain models have to cover the "entire world". Finally, it is an emotional and personality-based product that is associated with fun and that is driving inspiration and behavior. Thus, these non-rational components impose specific challenges for interfaces as well as for decision-making, recommender and highly personalized persuasion systems (which will pop up soon).

From the computer science point of view we highlight only some recent developments, e.g., Internet of Things and related disappearing interfaces, where IT is everywhere at any time. This calls for new forms of distributed computing with little latency, bringing us into the field of edge computing. IoT requires new search and 
recommender approaches that move away from textual search using the terminology of the suppliers to emotional, implicit, and sensor-based approaches. Also in this field promising application cases very often come from the tourism domain. Another important area is machine learning and/or artificial intelligence, where here we do not discuss the important difference between both. Referring to AI, a really interesting "project" would be a Turing test, tailored to the tourism domain. ${ }^{1}$

Just these two examples, combined with the specific features of the domain, show that, if one wants to interfere and influence this development with accelerating technology cycles, more emphasis on a computer science approach (with its formal and engineering leg) is needed-if one does not just want to observe. This is not a contradiction to the need for interdisciplinary research, when looking at the evolving complexity with respect to processes, structures and technology. Here we would like to point to the JITT research agenda (Werthner et al. 2015), which summarizes in an integrative and consistent form the open and most promising research issues in e-tourism, classified according to the concept of digital infrastructure with its five different layers, i.e., (1) individual, (2) group/social, (3) enterprise/corporation, (4) networks/industry, and, finally, (5) governmental/policy.

\section{Conclusions}

When looking at the tourism industry, it is obvious that IT has changed nearly everything; as it has also changed the tourism research field, with all its publications and meetings outlets. However, what we see is the diminishing role of IT-based and computer science-focused research in e-tourism research. Here, in scientific journals and at conferences, this topic is becoming increasingly rare. We would like to stress that computer science is central. Or stated otherwise: technology is not everything, but without it everything might be nothing,

Secondly, on a macro level IT-based innovation led to platforms and by and by to a monopolistic market structure. Thus, the focus - in the observational fieldshould not only be at the micro level, but by exploiting more and more large-scale data, at the macro level. We should not forget the "big picture".

The travel and tourism industry shows very well the metamorphosis of IT and its pervasiveness. Clearly, we will see further technology waves (as in the past). The journey has not ended. However, we should not only observe the journey, but contribute to its design and construction!

Acknowledgements Open access funding provided by TU Wien (TUW).

Open Access This article is distributed under the terms of the Creative Commons Attribution 4.0 International License (http://creativecommons.org/licenses/by/4.0/), which permits unrestricted use, distribution, and reproduction in any medium, provided you give appropriate credit to the original author(s) and the source, provide a link to the Creative Commons license, and indicate if changes were made.

\footnotetext{
1 Imagine, for example, a specific Turing test, mimicking a Travel Agent's counseling session, organized by JITT or IFITT. Research groups compete world-wide for the 500,000 Euro Price, sponsored by e-commerce and e-tourism companies, for passing as first the (probably slightly reduced and modified) Turing test.
} 


\section{References}

Buhalis D, Law R (2008) Progress in information technology and tourism management: 20 years on and 10 years after the Internet-The state of eTourism research. Tour Manag 29(4):609-623

Calatrava Moreno MDC, Hörhager G, Schuster R, Werthner H (2015) Strategic e-tourism alternatives for destinations. In: Information and communication technologies in tourism 2015 (pp 405-417), Springer, Cham

Cusumano M (2008) Technology strategy and management The puzzle of Apple. Commun ACM 51(9):22-24

Cusumano MA (2010a) Staying power: six enduring principles for managing strategy and innovation in an uncertain world (lessons from Microsoft, Apple, Intel, Google, Toyota and more) (Clarendon lectures in management studies). Oxford University Press, Oxford, pp 22-30

Cusumano MA (2010b) Technology strategy and management: the evolution of platform thinking. Commun ACM 53(1):32-34

Lazer D, Pentland AS, Adamic L, Aral S, Barabasi AL, Brewer D, Christakis N, Contractor N, Fower J, Gutmann M, Jebara T, King G, Macy M, Roy D, Van Alstyne M (2009) Life in the network: the coming age of computational social science. Science (New York, NY) 323(5915):721

Sertkan M (2018) Classifying and mapping e-tourism datasets. Master's Thesis, TU Wien

Wang D, Fesenmaier DR, Werthner H, Wöber K (2010) The journal of information technology and tourism: a content analysis of the past 10 years. Inf Technol Tour 12(1):3-16

Werthner H, Klein S (1999) Information technology and tourism: a challenging relationship. Springer, Wien

Werthner H, Ricci F (2004) E-commerce and tourism. Commun ACM 47(12):101-105

Werthner H, Alzua-Sorzabal A, Cantoni L, Dickinger A, Gretzel U, Jannach D, Neidhardt J, Pröll B, Ricci F, Scaglione M, Stangl B, Stock O, Zanker M (2015) Future research issues in it and tourism. Inf Technol Tour 15(1):1-15 